This item was submitted to Loughborough's Research Repository by the author.

Items in Figshare are protected by copyright, with all rights reserved, unless otherwise indicated.

\title{
Microwave-enhanced densification of sol-gel alumina films
}

PLEASE CITE THE PUBLISHED VERSION

http://dx.doi.org/10.1016/j.tsf.2007.10.095

\section{PUBLISHER}

(c) Elsevier

LICENCE

CC BY-NC-ND 4.0

\section{REPOSITORY RECORD}

Wang, Jianxin, J.G.P. Binner, Yongxin Pang, and Bala Vaidhyanathan. 2008. "Microwave-enhanced Densification of Sol-gel Alumina Films". figshare. https://hdl.handle.net/2134/3461. 
This item was submitted to Loughborough's Institutional Repository by the author and is made available under the following Creative Commons Licence conditions.

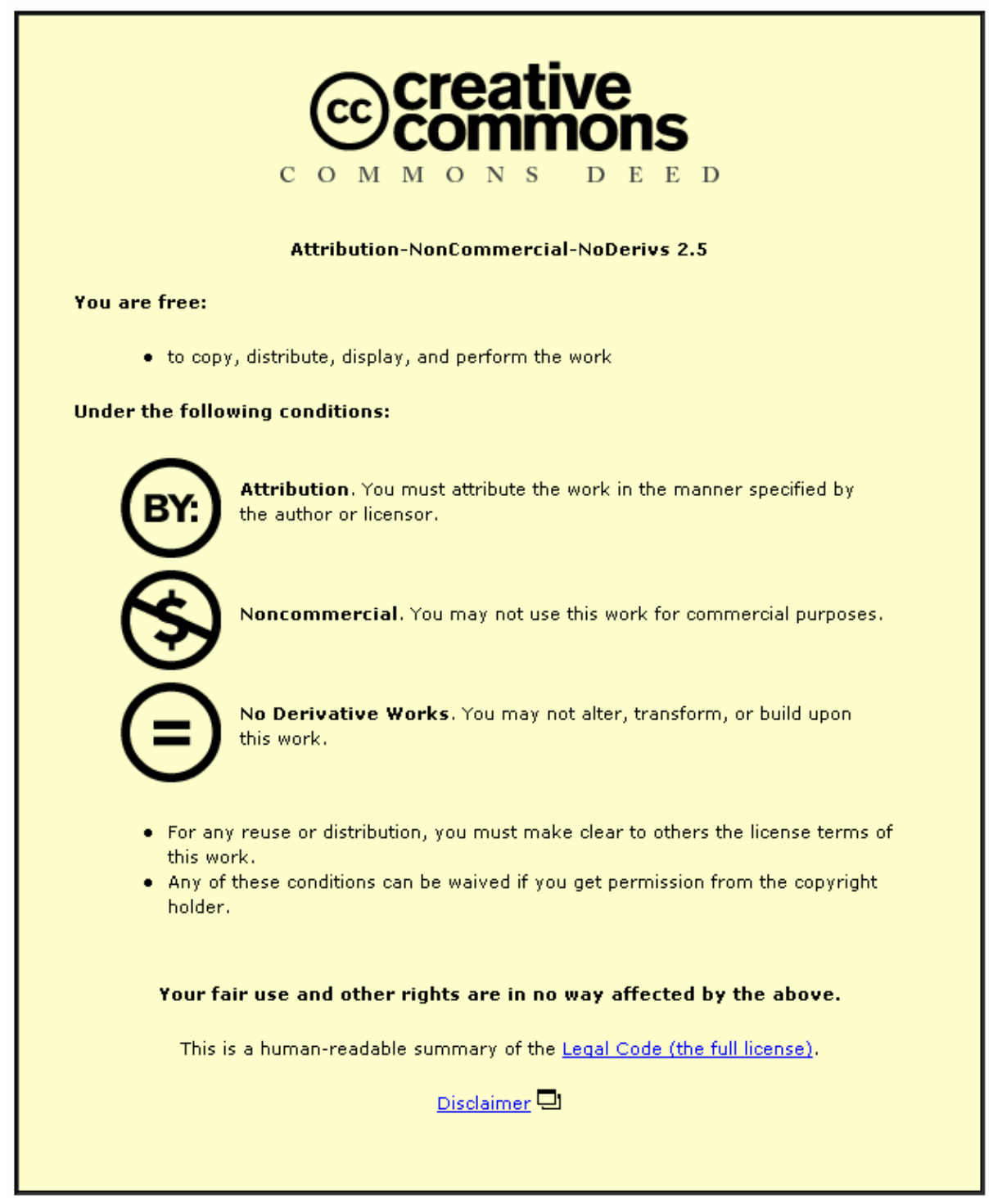

For the full text of this licence, please go to: http://creativecommons.org/licenses/by-nc-nd/2.5/ 


\title{
Microwave-enhanced densification of sol-gel alumina films
}

\author{
Jianxin Wang $^{\mathrm{a}, \mathrm{b}, *}$, Jon Binner ${ }^{\mathrm{a}}$, Yongxin Pang ${ }^{\mathrm{a}, \mathrm{c}}$, Balasubramaniam Vaidhyanathan ${ }^{\mathrm{a}}$ \\ ${ }^{a}$ IPTME, Loughborough University, Loughborough, Leicestershire, LE11 3TU, UK \\ ${ }^{b}$ Key Lab of Advanced Technologies of Materials, Ministry of Education, School of Materials Science and \\ Engineering, Southwest Jiaotong University, Chengdu, 610031, P. R. China \\ ${ }^{\mathrm{c}}$ School of Science and Technology, University of Teesside, Middlesbrough, TS1 3BA, UK
}

\begin{abstract}
Alumina films prepared by the sol-gel method were sintered at $1160{ }^{\circ} \mathrm{C}$ and $1200{ }^{\circ} \mathrm{C}$ using a $2.45 \mathrm{GHz}$ microwave / conventional hybrid furnace in order to study the influence of microwave power on the sintering process and resultant samples. Experiments were designed to ensure that each series of samples underwent an identical thermal history in terms of temperature / time profiles. Sintering was carried out using three different heating approaches: pure conventional heating and hybrid heating with $600 \mathrm{~W}$ and $1000 \mathrm{~W}$ of microwave radiation, respectively. The results obtained showed that, compared with pure conventional heating, the presence of the microwave field led to higher sintered densities and crystallinity in the samples, indicating that the microwave field enhanced the sintering of the sol-gel alumina films and supporting the existence of the microwave effect.
\end{abstract}

Key words: Microwave processing; alumina films; sintering; crystallization; the microwave effect 


\section{Introduction}

Microwave processing of ceramics has gained increasing attention in recent years because it has a number of distinct advantages over conventional thermal processing of ceramics, these include the potential for a fast heating rate, lower energy consumption and selective heating of specific regions or phases in a mixture or composite [1-3]. However, almost from the start, unexpected effects were found which appeared to result from the use of microwave radiation for ceramic processing, including, amongst others, accelerated kinetics and enhanced sintering of ceramic powder compacts [3-15]. These phenomena are generally known as the 'microwave effect'. Though a number of explanatory theories have been proposed in an attempt to gain a better understanding of this phenomenon [4-16], it is, nevertheless, still a controversial issue that often centres on accurate temperature measurement. For example, due to the nature of the energy deposition profile, during conventional heating the surface of a sample will be the hottest part due to the need for thermal conduction to transfer the energy to the centre of the body. In contract, with microwave heating the centre can be the coolest due to the development of an inverse temperature profile [17], hence, the actual sample temperature will be underestimated during microwave heating if only the surface temperature is monitored. In addition, the inability to vary the energy source without simultaneously affecting a wide range of other variables makes it extremely difficult to obtain quantitative information on the effect of microwave power level during the processing of materials, e.g. the sintering and annealing of ceramics. For example, whilst microwave heating experiments are performed in a microwave furnace, the corresponding conventional experiments are typically carried out in a separate radiant furnace of totally different specification (e.g., power level). Therefore, in order to ensure the accuracy of the experimental observation of any microwave enhancement, it is essential to avoid the occurrence of large temperature gradients and the inconsistency of using different heating systems with totally different specifications.

In this work, the microwave effect was investigated via the densification of thin alumina $\left(\mathrm{Al}_{2} \mathrm{O}_{3}\right)$ films, prepared by the sol-gel route, using a hybrid furnace that was constructed to operate under pure conventional, pure microwave or their simultaneous combination (hybrid heating) in the same furnace chamber and using the same temperature measurement system. This strategy was designed to eliminate temperature gradients and allowed all the samples processed under any given set of conditions to see identical thermal histories. 


\section{Experimental procedures}

\subsection{Preparation of the $\mathrm{Al}_{2} \mathrm{O}_{3}$ films}

Alumina sol was prepared via a traditional sol-gel route using aluminium tri-sec-tutoxide, isopropanol and nitric acid (all from Aldrich, UK) and deionised water in the molar ratio of $1.0: 2.0: 0.1: 50$. The ingredients were mixed and stirred at $85{ }^{\circ} \mathrm{C}$ for $24 \mathrm{~h}$ to yield a clear alumina sol. The latter was spread very thinly and uniformly on the bottom of square plastic weighing boats (from Aldrich, UK) and dried very slowly at room temperature to form uniform alumina xerogel films. These were then removed from the weighing boats and calcined at $500{ }^{\circ} \mathrm{C}$ for $1 \mathrm{~h}$ to remove the residual organics. The resulting films, which measured $\sim 0.18 \mathrm{~mm}$ in thickness and whose density was $\sim 50 \%$ of theoretical, were cut into $5 \times 5 \mathrm{~mm}$ square pieces for the sintering experiments.

\subsection{Densification of the $\mathrm{Al}_{2} \mathrm{O}_{3}$ films}

The primary aim of this sintering study was to expose the samples to varying levels of microwave and conventional power whilst ensuring that they all saw exactly the same temperature - time profile, including heating and cooling, so that direct comparisons between them could be made. Sintering temperature and soaking time were therefore deliberately selected to ensure that full densification was not achieved so that any differences as a result of the level of microwave power used could be observed. The densification of the alumina films was conducted at two different temperatures, 1160 and $1200^{\circ} \mathrm{C}$, for $1 \mathrm{~h}$ using exactly the same temperature / time profile whilst varying the fraction of microwave and conventional power used in a hybrid microwave furnace, figure 1 . The latter was capable of operating in a pure conventional, pure microwave or microwave / conventional hybrid mode; the microwave frequency was $2.45 \mathrm{GHz}$ and the maximum microwave power available was $1.2 \mathrm{~kW}$. The sample temperature was monitored by a single optical fibre thermometer, OFT (M100, Luxtron, USA) mounted vertically and touching the centre of the sample surface ${ }^{1}$. The use of a spring-loaded system permitted the OFT probe to maintain contact with the sample surface throughout the sintering cycle, ensuring accurate temperature measurement. For each sintering run within a

\footnotetext{
${ }^{1}$ Note: Fig 1 shows two OFTs, this was the arrangement used in related work [15]. In the case of the thin alumina films it was not possible to mount a second OFT horizontally to make contact with the outside edge of the sample.
} 
given series, the microwave power level was fixed at a given value, viz. $0 \mathrm{~W}$ (known as pure conventional, PC) and 600 and $1000 \mathrm{~W}$ (known as hybrid heating, H600 and H1000 respectively), and the conventional power varied to generate the same sintering schedule.

The accuracy of the temperature measurements was independently assessed using a separate series of measurements involving measuring the melting point of vanadium pentoxide; they were found to be within \pm 3 ${ }^{\circ} \mathrm{C}$ [18]. Since the optical fibre thermometers could not provide temperature measurements below $450{ }^{\circ} \mathrm{C}$, a 1 $\mathrm{h}$ hold at $500{ }^{\circ} \mathrm{C}$ was used to ensure thermal equilibrium was reached before the significant part of the experiment began when the microwaves were switched on and the sample heated to the sintering temperature. Throughout the work, at least five sintering experiments were performed under the same conditions to generate each data point. Two further samples, one calcined at $500{ }^{\circ} \mathrm{C}$ for $1 \mathrm{~h}$ and designated 'unsintered' and the other sintered conventionally at $1200^{\circ} \mathrm{C}$ for $12 \mathrm{~h}$ to ensure full transition into $\alpha$-alumina, were used for comparison. The later is called ' $\alpha$-alumina' in the sections below.

\subsection{Characterisation}

The green sample densities were estimated by simple measurement of the sample dimensions and mass, whilst the sintered densities were measured by the Archimedes method using deionised water containing 0.2 wt. $\%$ polyvinylacohol surfactant of average $\mathrm{M}_{\mathrm{w}} 13,000-23,000,98 \%$ hydrolyzed (from Aldrich, UK).

The phase analysis of all the samples was conducted using X-ray diffraction, XRD (Bruker AXS D8 Advances) with $\mathrm{Cu} K \alpha$ radiation at $40 \mathrm{kV}$ and $40 \mathrm{~mA}$. Data was collected over the $2 \theta$ range from 20 to $70^{\circ}$ in a step size of $0.02^{\circ}$ and a step time of $1 \mathrm{~s}$. In order to obtain a quantitative estimation of the relative phase composition using the intensity of the diffraction peaks, samples were first ground into powders for the XRD measurements and then $0.1 \mathrm{~g}$ of ground powder was dispersed in acetone and uniformly spread across the $20 \times 20 \mathrm{~mm}$ area of the sample stage and then dried. 
The analysis of the film composition was obtained by FTIR spectrometry (Mattson 3000, Unicam Ltd., England). 1mg of each tested sample was carefully mixed with $300 \mathrm{mg}$ of $\mathrm{KBr}$ (infrared grade) and ground and then pressed into discs for the measurements. The spectra were recorded from 400 to $4000 \mathrm{~cm}^{-1}$ wavenumber at $4 \mathrm{~cm}^{-1}$ resolution, averaging 64 scans.

In addition, the microstructure and surface morphology of the sintered alumina films were observed using a field emission gun scanning electron microscope, FEG-SEM (Leo 1530VP UK). The working distance was $6 \mathrm{~mm}$ and the accelerating voltage of the electron beam was $5 \mathrm{kV}$. A gold coating was evaporated onto the sample surface prior to analysis to increase the electrical conduction of the films.

\section{Results and discussion}

\subsection{Observation of crystallization and densification}

The results of the XRD measurements are shown in figure 2. It can be seen that the unsintered sample comprised the $\gamma$-phase, whilst the sample sintered at $1200{ }^{\circ} \mathrm{C}$ for $12 \mathrm{~h}$ only showed diffraction peaks for $\alpha$-alumina. Samples sintered with PC and H1000 heating primarily showed the diffraction pattern of $\alpha$-alumina [19] although a small wide peak that may be assigned to $\delta$-alumina was also detected [20]. However, it can be clearly observed that the diffraction peaks' intensities were much stronger for the H1000-heated samples than those sintered using PC heating. As stated in the experimental section, the samples' mass and area on the sample stage for the XRD measurements were the same, as a result the amount of materials subject to X-ray irradiation should have been the same as well and it is thus reasonable to assume that the intensity of the diffraction peak was proportional to the phase amount in the sample. The intensities of the diffraction peaks at $2 \theta=43.38^{\circ}$ obtained by integration of the peak areas are listed in Table 1 . The stronger diffraction peaks for the sample sintered using H1000 heating compared to that heated conventionally (PC) strongly suggests that it underwent a higher degree of phase transformation. 


\begin{tabular}{|l|c|c|c|}
\hline & $\begin{array}{c}\text { Pure conventional } \\
1200{ }^{\circ} \mathrm{C} / 1 \mathrm{~h}\end{array}$ & $\begin{array}{c}\text { Hybrid }(1000 \mathrm{~W}) \\
1200{ }^{\circ} \mathrm{C} / 1 \mathrm{~h}\end{array}$ & $\begin{array}{c}\text { Reference } \\
1200{ }^{\circ} \mathrm{C} / 12 \mathrm{~h}\end{array}$ \\
\hline FTIR: $\mathrm{I}_{452} / \mathrm{I}_{504}$ & 1.4 & 1.9 & 3.2 \\
\hline XRD: $2 \theta=43.38^{\circ}$ & 8.9 & 12.8 & 21.6 \\
\hline
\end{tabular}

Table 1. Relative amounts of the $\alpha$-phase present as calculated from FTIR and X-ray diffraction data.

Figure 3 shows the FTIR spectra for the different samples. The unsintered sample displayed a strong broad peak at $3450 \mathrm{~cm}^{-1}$ and a medium-sized sharp peak at $1628 \mathrm{~cm}^{-1}$, both attributed to surface hydroxyl groups [21], which reduced significantly after sintering. The latter peak, the small triple peaks around $1388 \mathrm{~cm}^{-1}$ and the broad strong double bands from 800 to $570 \mathrm{~cm}^{-1}$ can all be assigned to $\gamma$-alumina [21,22]. In addition to the reduction of the hydroxyl groups, sintering also led to the development of peaks at $1738 \mathrm{~cm}^{-1}, 1094 \mathrm{~cm}^{-1}, 620$ $\mathrm{cm}^{-1}$ and $452 \mathrm{~cm}^{-1}$, which are related to the crystallization of the samples as a result of sintering. However, the bands at 1738 and $1094 \mathrm{~cm}^{-1}$ were not found in the spectrum for the 'reference' $\alpha$-alumina sample sintered at $1200{ }^{\circ} \mathrm{C}$ for 12 hours. As shown by the XRD results in figure 2, a very small amount of $\delta$-alumina was detected in the samples sintered with PC and H1000 heating that were not present in the longer sintered reference sample. This suggests that these peaks might be attributable to this crystalline phase, though further evidence would be required for confirmation. The sharp peak at $452 \mathrm{~cm}^{-1}$ and the double peak at $620 \mathrm{~cm}^{-1}$ may be assigned to the $\alpha$-phase [22,23], corresponding to Al-O vibrational modes. The intensities of these absorption bands changed with the different heating approaches however, with the H1000 heating resulting in much stronger peaks than the PC heating, again indicating that the use of microwave power enhanced the crystallinity of the sintered samples.

It may also be noted that the absorption bands of the normalised FTIR spectra changed systematically with the different heating approaches, particularly between 400 and $1000 \mathrm{~cm}^{-1}$. This provided the opportunity to analyse the spectra semi-quantitatively. The intensity ratio of the $452 \mathrm{~cm}^{-1}$ peak to the trough at $504 \mathrm{~cm}^{-1}$ was chosen as representative since this band was well-defined and only from the $\alpha$-phase. The results are listed in 
Table 1 and are in good agreement with the data calculated from the XRD spectra. On this basis, the amount of $\alpha$-phase developed by $\mathrm{H} 1000$ heating was about 36\% higher than that when PC heating was utilised.

Figure 4 shows the microstructures of the alumina films before and after sintering at $1160{ }^{\circ} \mathrm{C}$ using pure conventional heating and hybrid heating. It can be seen that all of the sintered films displayed nano-sized grains and pores. Whilst the level of coarsening of the particles was approximately the same in the PC and H600 samples, the nanostructure displayed by the H1000 samples was significantly coarser. This supports the argument that the microwave field has promoted the densification process during sintering, in agreement with the above results. Similar results may be observed for the samples sintered at $1200{ }^{\circ} \mathrm{C}$, figure 5 , although, due to the higher temperature, considerably more densification and grain growth has occurred in all cases. Once again though, the H1000 sample has clearly sintered the greatest amount. Figure 6 shows the measured densities of the sample films as a function of the level of microwave power used; this data again confirms the other results presented to date. Even though the same temperature / time profile has been used in each case $( \pm 3$ ${ }^{\circ} \mathrm{C}$ throughout, cold to cold), the final density has been enhanced when microwaves were used by $\sim 3 \%$ for the H600 samples at both temperatures and by $5 \%$ and $7 \%$ for the $\mathrm{H} 1000$ samples at 1160 and $1200{ }^{\circ} \mathrm{C}$ respectively. These results are in good agreement with those obtained elsewhere [15].

\subsection{Densification mechanism and possible explanation for the effect of microwave during microwave hybrid} sintering of sol gel alumina films

Bykov et al [11] reported a comparative study of pore evolution in nanostructured alumina membranes during sintering in a $10 \mathrm{~kW}, 30 \mathrm{GHz}$ gyrotron microwave system and a conventional furnace; their results clearly showed the enhancement of mass transport in the microwave field. However, the densification process was only associated with the shrinkage of pores and the grains were difficult to detect.

Previous work by our group using the same pure conventional and hybrid heating approach for different ceramics [15] demonstrated that the magnitude of the microwave effect was related to the degree of microwave absorption by the material; thus the effect was largest in zinc oxide, intermediate in zirconia and 
negligible in alumina. Whilst the latter result would appear at first sight to be at odds with the current results, it is believed that there will have been significant differences between the production of 'bulk' alumina samples and the thin films used in the present work that will have had significantly higher surface areas and hence greater potential for the effect to occur. The differences in the degree of crystallinity of the starting precursors would also have contributed to the effect.

The sintering mechanisms for ceramics include lattice, surface and grain-boundary diffusion as well as the rearrangement and agglomeration of particles in compacts or films consisting of nanoparticles. From the experimental results obtained in the current work, it can be seen that microwaves clearly enhanced the densification of sol gel alumina films not only in the initial stage but also in the intermediate stage. A plausible reason is that microwaves provide an additional driving force for mass transport as reported by Rybakov et al $[12,13]$. They suggest that the steady-state vacancy flows resulting from the pondermotive effect can contribute to the densification. Compared to microcrystalline materials, the large fraction of interface regions in the nanocrystalline materials, more space charges on grain boundaries and smaller pores and grains would appear to have made this pondermotive effect more pronounced [16].

\section{Conclusions}

Alumina films prepared by a sol-gel route have been sintered using pure conventional (radiant) heating and hybrid microwave / conventional heating using two different microwave power levels, although in each case the temperature / time profile was identical for each set of experiments. The results of X-ray diffraction, FTIR measurements and a study of the density and microstructure of the resulting samples all suggest the same result, that the use of microwaves has enhanced the densification process. In each case, the hybrid heated samples using $600 \mathrm{~W}$ were more densified and had undergone greater phase transformation from the $\gamma$ to the $\alpha$ phase than those heated using pure conventional heating. Similarly, when $1000 \mathrm{~W}$ of microwaves were used the degree of densification and phase transformation were enhanced further. These results therefore support earlier work performed on the sintering and annealing of bulk ceramics $[15,24]$ that indicated that the so-called 'microwave effect' is genuine, at least during ceramic densification. Whilst no definitive mechanism 
has arisen from this work, the results are consistent with the ponderomotive effect reported in the work by Rybakov et al [12,13].

\section{Acknowledgment}

This work was supported by the Engineering and Physical Sciences Research Council (EPSRC) in the UK under grant reference GR/R52435.

\section{References}

[1] L.M. Sheppard, Am. Ceram. Soc. Bull. 67 (1988) 1656.

[2] W.B. Harrison, M.R.B. Hanson, B.G. Koepke, in: W.H. Sutton, M.H. Berton, I.J. Chabinsky (Eds), Microwave Processing of Materials, Mater. Res. Soc. Symp. Proc., vol. 124, 1988, p. 279.

[3] J.D. Katz, R.D. Blake, Am. Ceram. Soc. Bull. 70 (1991) 1304.

[4] A. Birnboim, D. Gershon, J. Calame, A. Birman, Y. Carmel, J. Rodgers, B. Levush, Y.V. Bykov, A.G. Eremeev, V.V. Holoptsev, V.E. Semenov, D. Dadon, P.L. Martin, M. Rosen, R. Hutcheon, J. Am. Ceram. Soc. $81(1998) 1493$.

[5] S.A. Nightingale, H.K. Worner, D.P. Dunne, J. Am. Ceram. Soc. 80 (1997) 394.

[6]Y. Fang, J.P. Cheng, R. Roy, D.M. Roy, D.K. Agrawal, J. Mater. Sci. 32 (1997) 4925.

[7] S. Gedevanishvili, D. Agrawal, R. Roy, J. Mater. Sci. let. 18 (1999) 665.

[8] J.P. Cheng, D. Agrawal, Y.J. Zhang, R. Roy, J. Mater. Sci. lett. 20 (2001 ) 77.

[9] S. Mandal, A. Seal, S.K. Dalui, A.K. Dey, S. Ghatak, A.K. Mukhopadhyay, Bull. Mater. Sci. 24 (2001) 121.

[10] X. Fan, R.M. Kelly, N.A. Rowson, Canad. Metal. Quart. 39 (2000) 247.

[11] Y.V. Bykov, S.V. Egorov, A.G. Eremeev, K.I. Rybakov, V.E. Semenov, A.A. Sorokin, S.A. Gusev, J. Mater. Sci. 36 (2001) 131.

[12] K.I. Rybakov, V.E. Semnov, Phys. Rev. B 49 (1994) 64.

[13] K.I. Rybakov, V.E. Semnov, Phys. Rev. B 52 (1995 ) 3030.

[14] M.A. Janney, H.D. Kimrey, M. Schmidt, J. Kiggans, J. Am. Ceram. Soc. 74(1991) 1675. 
[15] J. Wang, J. Binnerjavascript:popRef('c1'), B. Vaidhyanathan, N. Joomun, J. Kilner, G. Dimitrakis, T.E. Cross, J. Am. Ceram. Soc. 89 (2006) 1977.

[16] A. Birnboim, J.P. Calame, Y. Carmel, J. Appl. Phys. 85 (1999) 478.

[17] J.G.P. Binner, T.E. Cross, in: R.L. Beatty, W.H. Sutton M.F. Iskander (Eds), Microwave Processing of Materials III, Mat. Res. Soc. Proc., vol. 269, 1992, p. 357.

[18] J.G.P. Binner, B. Vaidhyanathan, J. Wang, in: J.G.P. Binner(Ed), Proceedings of the 9th International Conference on Microwave and High Frequency Heating, Loughborough, UK, September 1-5, 2003, p. 477.

[19] Y.X. Pang, X. Bao, J. Mater. Chem. 12 (2002) 1.

[20] D. Fargeot, D. Mercurio, A. Dauger, Mater. Chem. \& Phys. 24 (1990) 299.

[21] H.A. Dabbagha, M. Yalfania, B.H. Davis, J. Molec. Catal. A: Chemical 238 (2005) 72.

[22] C.H. Shek, J.K.L. Lai, T.S. Gu, G.M. Lim, Nanostruct. Mater. 8 (1997) 605.

[23] J. Li, Y. Pan, C. Xiang, Q. Ge, J. Guo, Ceram. Int. 32 (2006) 587.

[24] J. Binnerjavascript:popRef('c1'), J. Wangjavascript:popRef('c1'), B. Vaidhyanathan, N. Joomun, J. Kilner, G. Dimitrakis, T.E. Cross, J. Am. Ceram. Soc. 90 (2007) 2693. 
Figures

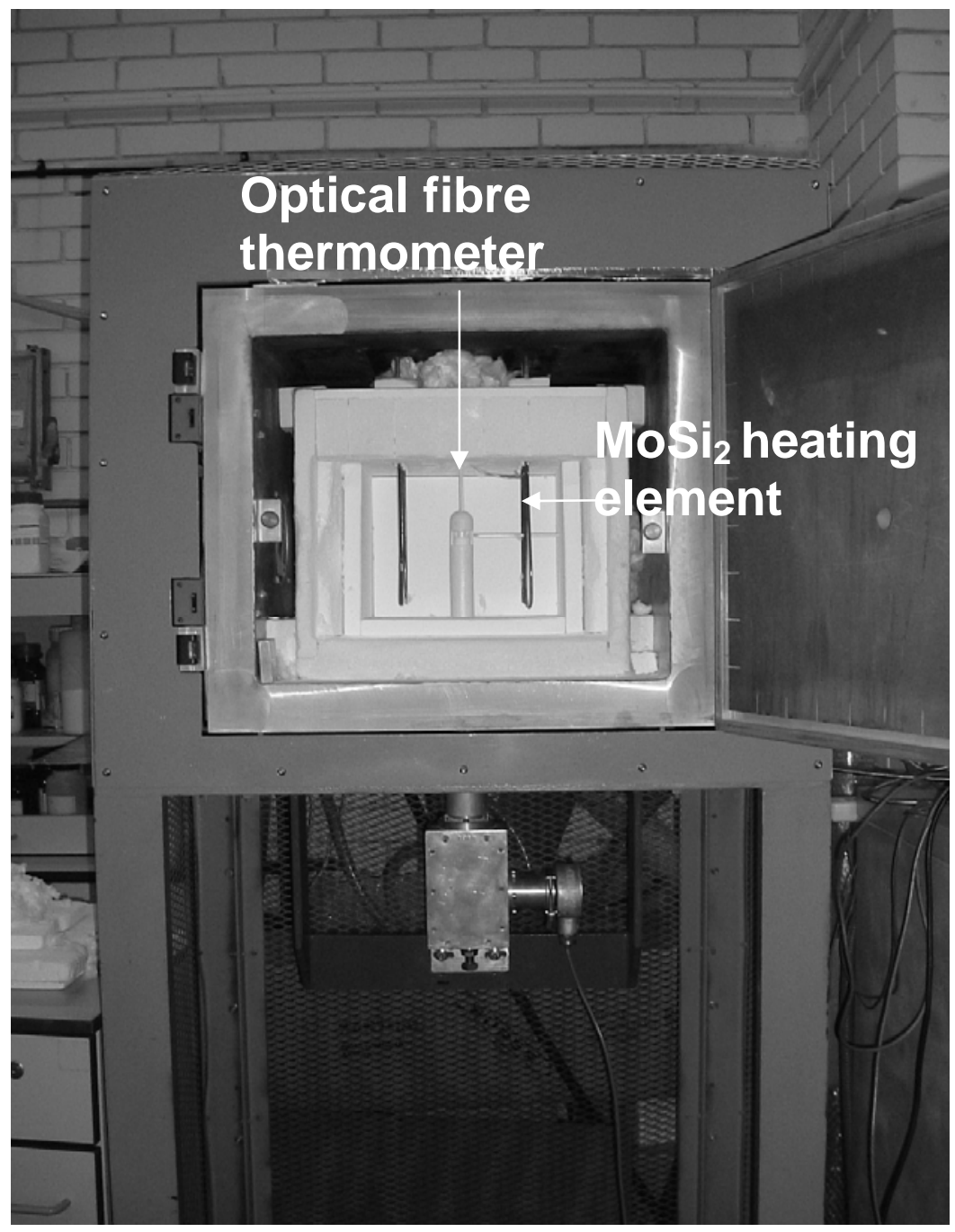

Figure 1. The hybrid microwave furnace used in the present work. 


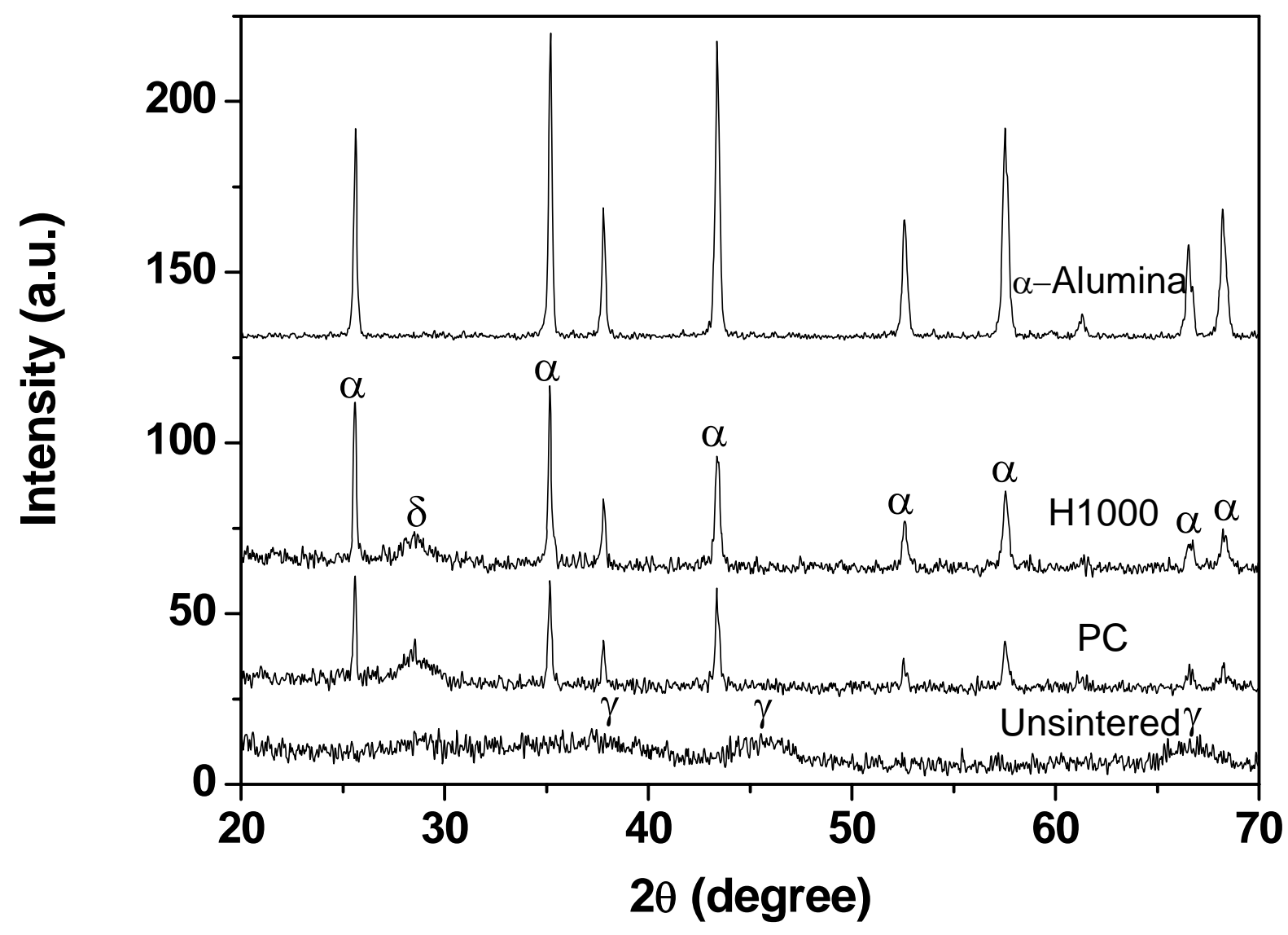

Figure 2. XRD patterns of samples sintered at $1160^{\circ} \mathrm{C}$ using pure conventional (PC) and hybrid heating with $1000 \mathrm{~W}$ of microwaves (H1000), together with reference patterns for the unsintered film and pure $\alpha$-alumina. 


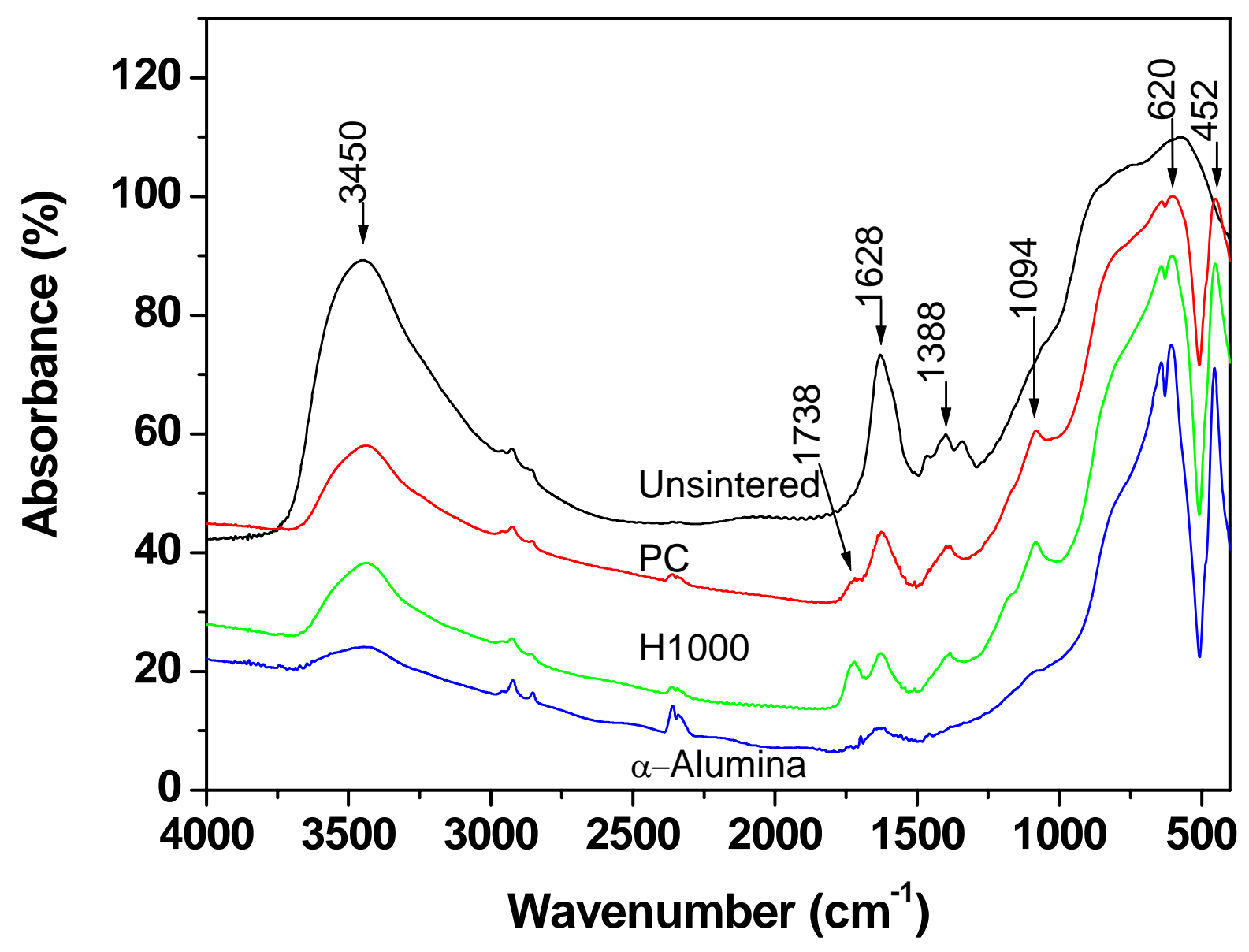

Figure 3. FTIR spectra of samples sintered at $1160^{\circ} \mathrm{C}$ using pure conventional (PC) and hybrid heating with $1000 \mathrm{~W}$ of microwaves (H1000), together with reference patterns for the unsintered film and pure $\alpha$-alumina. The spectra are normalised and off-set for clarity. 

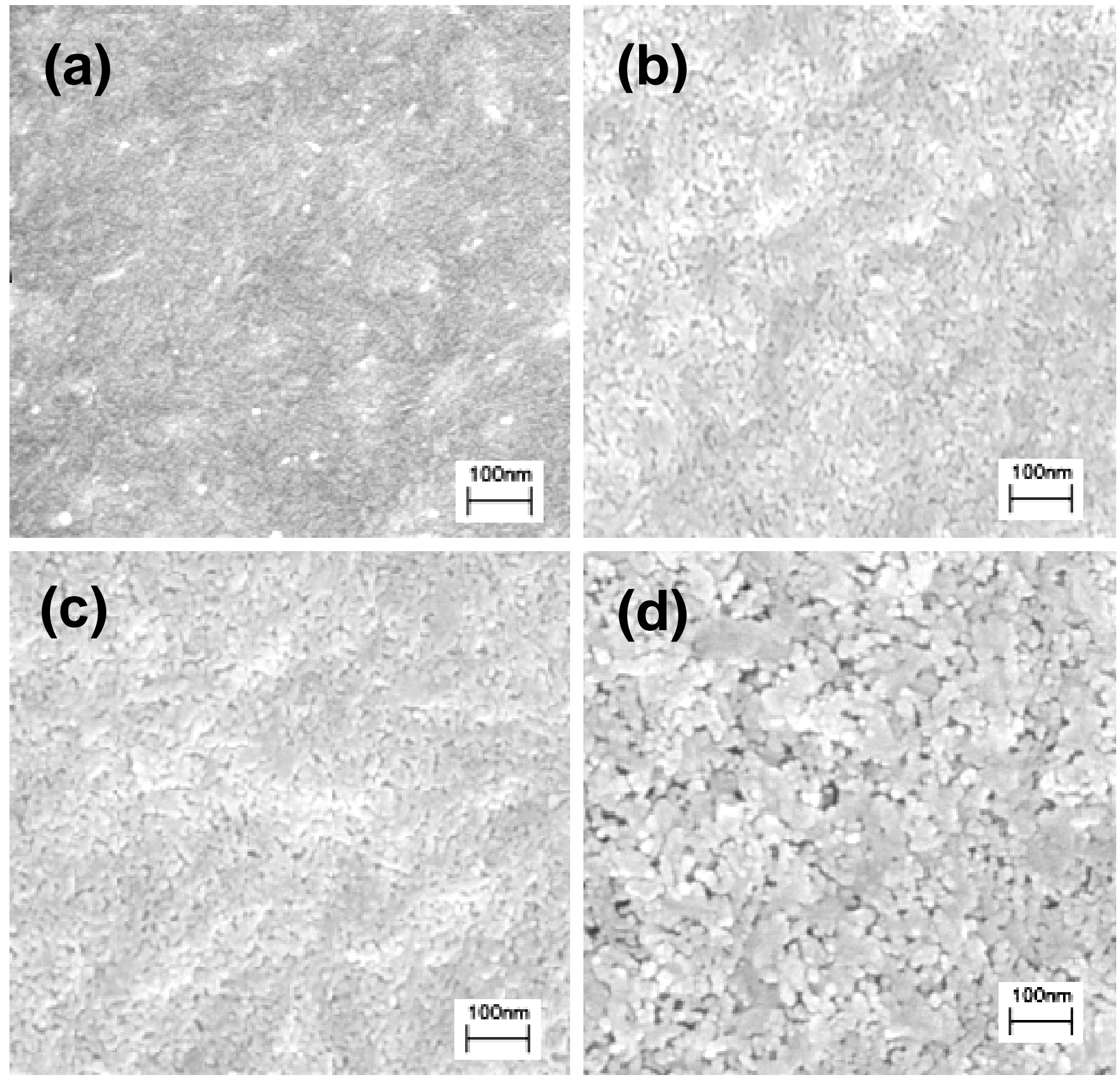

Figure 4. FEG-SEM micrographs of the surfaces of the sol gel alumina films, (a) before sintering and (b-d) after sintering at $1160{ }^{\circ} \mathrm{C}$ using pure conventional heating and hybrid heating with $600 \mathrm{~W}$ and $1000 \mathrm{~W}$ of microwave power, respectively. 


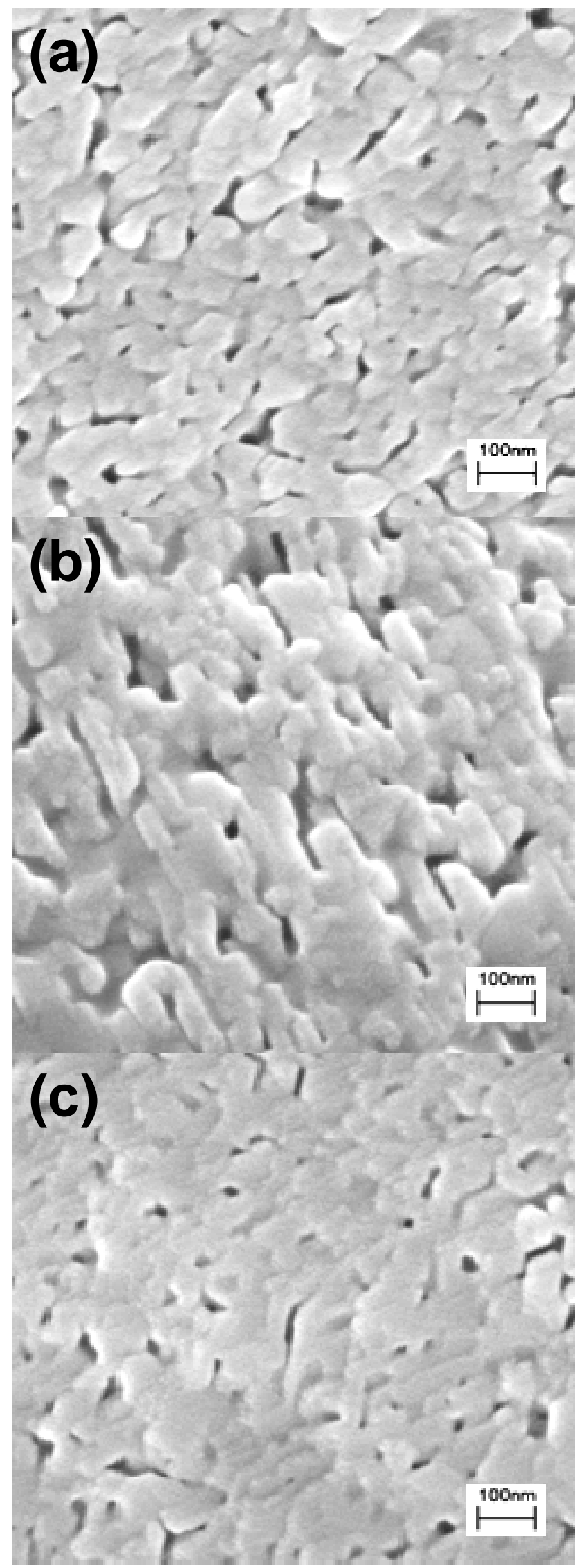

Figure 5. FEG-SEM micrographs of the surfaces of the sol gel alumina films after sintering at $1200{ }^{\circ} \mathrm{C}$ using (a) pure conventional heating, (b) hybrid heating using $600 \mathrm{~W}$ of 
microwaves and (c) hybrid heating using $1000 \mathrm{~W}$ of microwave power.

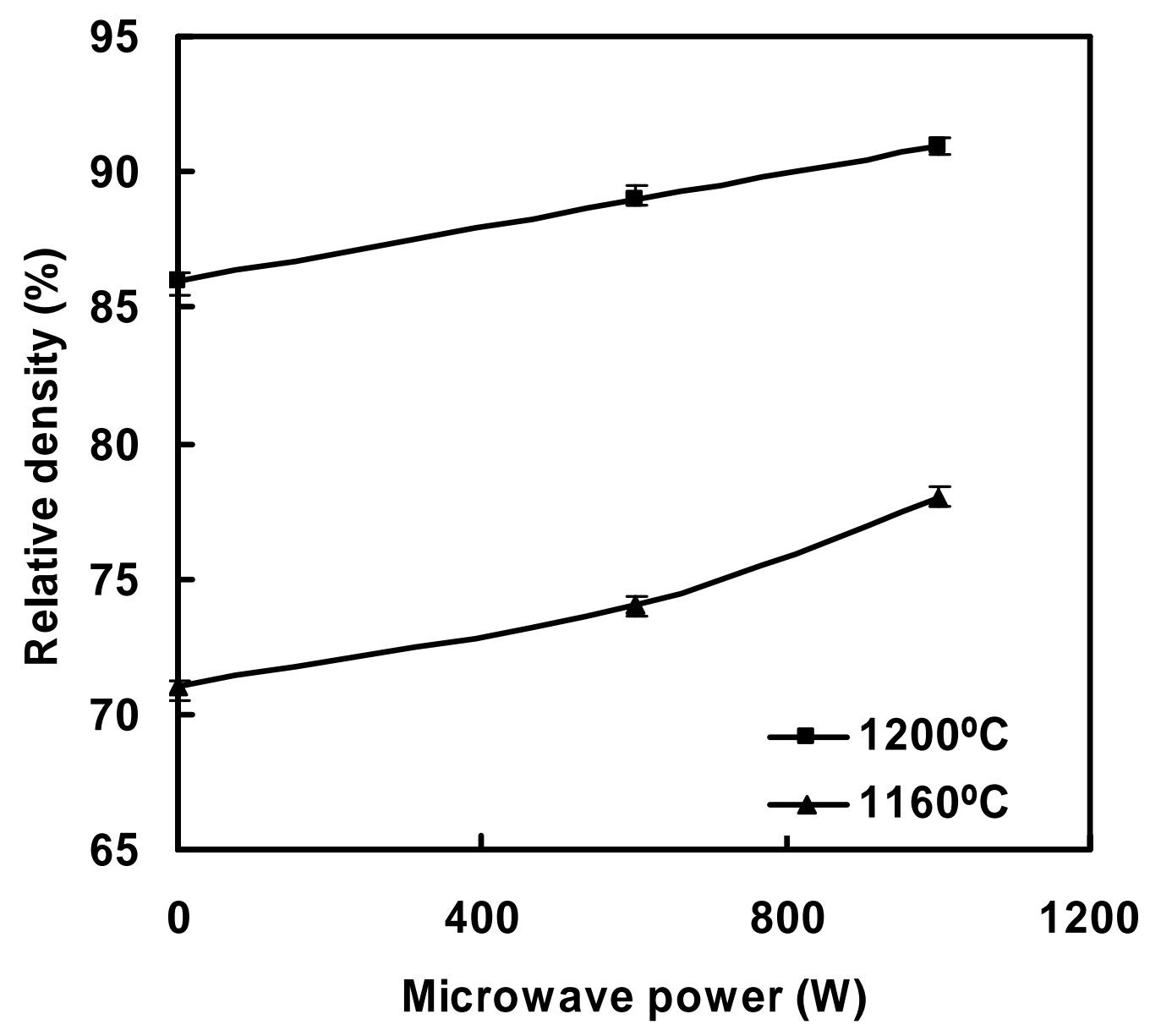

Figure 6. Changes in the density of the sintered alumina films as a function of the level of microwave power used. 